emphasised in connexion with food storage and transport. Sir William Hardy's fruitful work along these lines was fittingly described by Sir Frank. Thanks largely to the work of Sir William, it is realised to-day that the biologist must formulate the condition required in food storage and transport, and the engineer provide those conditions. The problems of the biologist concern not only methods of refrigeration itself, but also cleanliness, damage to foods by cold, etc. The most recent developments in gas storage using carbon dioxide, and in the storage of living material such as fruit, were also discussed by Sir Frank.

\section{Cleansing of Oysters}

THE cleansing of oysters on a commercial scale has now been accomplished after a period of some fifteen years' continuous research work at the Conway Experimental Station of the Ministry of Agriculture and Fisheries. A purification station has been established at Brightlingsea, and since May has produced 'certified' American and Portuguese oysters. The principles of the process are almost the same as those involved in the cleansing of mussels, namely, a thorough preliminary cleansing of the outside of the shell is followed by a first and then a second bath in sterilised water. During immersion in the baths the oysters cleanse themselves internally and externally (that is, the external soft parts inside the shell) of bacteria in a simple way; the internal bacteria are expelled. from the gut in the fæces, the external in mucoid films which are gleaned from all parts by cilia to be collected and extruded in masses as pseudo-fæces. After each bath, the shells are thoroughly washed to remove the excreta and are finally treated with water containing three parts in a million of free chlorine to destroy any remaining adherent germs. An essential feature of the oyster-cleansing process consists in the use of water at a temperature not less than $56^{\circ} \mathrm{F}$., as it was found after a long series of experiments that ciliary activity below this temperature could not be relied upon to effect perfect cleansing. Mussels can be reliably purified in water which does not fall below $39^{\circ} \mathrm{F}$. The English native (or European) oyster (Ostrea edulis) has been purified in a process involving three baths, and differs otherwise in its reactions from the American and Portuguese. It is reported that purified $O$. edulis may be produced in the coming winter. The summer capacity of the tanks is 360,000 oysters per week, but in winter when the sea-water requires to be warmed, the capacity is halved. Full details of the process and the plant are not yet available, but may be published in the near future.

\section{The Droitwich Broadcasting Station}

IN the presence of representatives of the Press, the new B.B.C. transmitting station at Droitwich was formally opened on September 6, to take over a part of the National broadcasting programme, This station will ultimately provide a full national programme from the long-wave transmitter which is now working, and also a regional service for the Midlands from a medium wave transmitter which will be completed in about six months' time. The programme transmitted from the new station on the opening day was heard in London very clearly, and its volume was considerably greater than that of tho London National transmitter at Brookman's Park. It is expected that the new long-wave station will give a service of such quality over so large an area of Great Britain that three other national stationsthose for London, the West and the North-will not need to go on broadcasting. The wave-lengths thus released may be used for other British stations to be erected in the future. The wave-length of the new Droitwich transmitter is identical with the long-wave Daventry station so that no change is required in listener's receiving sets.

THe issue of World Radio of September 7 contains an illustrated technical description of the new transmitting station at Droitwich, by Mr. Noel Ashbridge, chief engineer of the B.B.C. This transmitter has an aerial input power of $150 \mathrm{kw}$., five times as great as that of Daventry. The whole of the power for the station is generated by heavy oil engines, and these prime movers together with the electrical machines and their control equipment occupy a considerablo proportion of the space in the station buildings. The long-wave wireless transmitter consists of five units, by means of which, weak oscillations of a carefully controlled radio frequency are amplified up to a final output power of $150 \mathrm{kw}$. Modulation is carried out at the penultimate stage by varying the hightension supply to the anodes of the high-frequency valves, with which the modulating valves are in series. This method of modulation, together with a special output circuit arrangement, makes it possible for this transmitter to emit broadcasting programmes of a much superior quality to that hitherto possible from a long-wave station. The quality of the transmissions from Droitwich is expected to be at least equal to, and probably better than, those at present obtainable from the medium-wave stations. The new station is now radiating the morning National programme from 10.15 A.M. until 11.55 A.M. and the late dance music every week-day; it will continue to do this until it takes over the full service of the National programme from Daventry in October.

\section{Edinburgh Geological Society Centenary}

THE centenary of the Edinburgh Geological Society was celebrated on Monday and Tuesday, September 3 and 4. A considerable number of invitations had been sent out to kindred societies and institutions both at home and abroad, and a most gratifying response was received. On Monday morning the delegates were received by the president of the Society, Sir John Flett. Naturally the majority came from Scotland and England, but out of a total of sixty visitors, thirteen came from the Continent, nine represented the Colonial Empire, and four the United States of America. Following this reception, the whole party, including many fellows of the Society, had lunch in the city and proceeded to visit the Royal Scottish Musoum, where the various exhibits were demon- 